\title{
Analysis on Evaluation System of Scientific Research in German Universities and Its Enlightenment*
}

\author{
Lihong Li \\ School of Humanities and Law \\ Northeastern University \\ Shenyang, Liaoning, China 110819 \\ Liaoning TV \& Radio University Liaoning Vocational \\ College of Equipment Manufacture \\ Shenyang, Liaoning, China 110161
}

\author{
Wanbing Shi \\ School of Humanities and Law \\ Northeastern University \\ Shenyang, China 110819
}

\begin{abstract}
Essentially, the evaluation system of scientific research in universities conforms to the development pattern of scientific research and the historical tradition of education. University tradition supports the development direction of scientific research evaluation. German "Humboldt" tradition regards scientific research as function of university, academic freedom as precondition to do scientific research, contributing high academic standard of German universities. Although the scientific research evaluation in Germany starts later than that of America, it establishes multidimensional evaluation system of scientific research and centers on peer review with quantitative analysis as supplement. The system attaches importance to training of young scholars. Referential experience in establishing guarantee system of evaluation quality has important significance on establishing and improving evaluation and management systems of scientific research in Chinese universities.
\end{abstract}

Keywords-evaluation system of scientific research; German universities; analysis; enlightenment

\section{INTRODUCTION}

Although German scientific research evaluation starts later than that of America, it is internationally recognized that its evaluation system is diversified and rigorous. With increasing attentions paid to scientific research evaluation, Germany has plentiful experience in evaluating scientific research performance and normative system of peer review and forms the evaluation system of scientific research in which government agencies (BMBF and Excellence Initiative), third parties (Wissenschaftsrat, DFG, CHE and Alexander von Humboldt Foundation) and university self-evaluation supplement each other. Analysis on evaluation system of scientific research in German universities will enlighten the establishment and improvement of evaluation system of scientific research in Chinese universities.

*Fund project: National social science foundation education project "Research on Evaluation System of Scientific Research Performance of Teachers in Humanities and Social Sciences in Universities" (Project No.: BFA150043)

\section{EVALUATION OF GERMAN GOVERNMENT AGENCIES ON SCIENTIFIC RESEARCH IN UNIVERSITIES}

\section{A. The $B M B F$}

BMBF proposes education and scientific research are future of countries and the world. Promoting the development of education and scientific research is an important measure to guarantee national prosperity. BMBF is divided into eight departments: central administration, strategy and policy, European and international education and research collaboration, vocational training, lifelong learning, scientific system, key technology-innovation research, life scienceshealth research, future preparation-cultural, basic and sustainable research. In 1997, BMBF proposed "Germany puts funds into peer review", collecting funds of certain proportion (5 percent in general) from research institutions and universities and giving it to the third party DFG and reallocating the funds through peer review. BMBF formulates policies related to scientific research evaluation. Scientific research evaluation is done by third-party evaluation organizations.

\section{B. Scientific Evaluation of Excellence Initiative}

In July 2005, German Federal Government and state government officially signed "Agreement of Federation and State on Implementation of Excellence Initiative in German Universities". It stipulates BMBF authorizes DFG and WR to share responsibility in the Excellence Initiative, to investigate the excellent achievements of universities in three aspects: graduate school, excellence cluster and future conception, and support financially. At present, the Excellence Initiative has finished two phases. Eleven universities have received this honor. 85 percent of evaluation experts who participate in the Excellence Initiative come from foreign countries. The project adopts not lifelong tenure but rolling tenure. Excellence Initiative is the evaluation of government on universities and provides extra scientific research funds for universities. [1]

The scientific research evaluation of German Excellence Initiative develops in reform. For example, Germany is always famous for philosophy, sociology and cultural science. 
However, the first round of phase I of Excellence Initiative fails to fund traditional predominant disciplines in German universities. In the second round, German Federal Government specially defines 2007 as the "Year of Humanities and Social Sciences" to approve considerable special funds of 623 million Euros for humanities and social sciences. [2]

\section{THIRD-PARTY SCIENTIFIC RESEARCH EVALUATION ORGANIZATIONS}

\section{A. The Wissenschaftsmt}

Wissenschaftsmt is the earliest organization that provides policy advisory for scientific research in Europe. It was founded in 1957, referring to the first German organization that surveys the scientific research of Germany and provides suggestions for federation and state governments on scientific research funding. Wissenschaftsmt mainly researches the development of scientific research system, especially in universities and reforms policies of scientific research and universities. Since the 1980s, Wissenschaftsmt has established evaluation system of scientific research performance and has formed scientific evaluation system according to evaluation, promotion procedures and research rank as well as innovation approach.

In 2004, Wissenschaftsmt determined to evaluate all German universities. In July 2005, the evaluation plan entered testing phase. Test evaluation results of sociology and chemistry were issued in December 2007 and April 2008 respectively. Wissenschaftsmt evaluates researches on discipline of sociology according to six standards: research quality, research impact, research efficiency, training of young scholars, knowledge transformation and consultation based on research and scientific communication. [3]

In 2011, Wissenschaftsmt passed Suggestions on Scientific Research Performance Evaluation and Supervision Methods. Internal evaluation procedures of universities and scientific research institutions must be complicated, diversified, applicable and self-reflective, consider time period of testing and economic evaluation cost when guaranteeing evaluation quality. It states guidelines, index adjustment, method improvement and concrete measures about evaluation and supervision of scientific research performance, becoming the guide for Wissenschaftsmt and other German scientific and technological organizations to evaluate scientific research performance. Evaluation criterions of research-oriented scientific research institutions include: (1) quality of scientific research project; (2) outputs of publication, academic conference and patent; (3) internal quality control; (4) collaboration; (5) implementation of research results. [4]

Wissenschaftsmt requires evaluation organizations to publicize evaluation criterions and methods, channels and procedures as soon as possible. Evaluation data derive from stable and authoritative international open publications. They carry out pertinent peer review on evaluation objects through quantitative analysis and publicize the results. The period of evaluation on universities and other scientific research institutions is five to ten years per time. [5] The research evaluation of Wissenschaftsmt bases on procedures of peer review and principles of scientific evaluation. The results are qualitative evaluation on universities and academic institutions and consist of five grades, namely excellent, good, medium, satisfactory and dissatisfactory. The evaluation results have nothing to do with scientific research funds and only provide references for universities and academic institutions in strategic decision-making. [6]

\section{B. The $D F G$}

DFG is an independent funds management organization in order to promote the scientific research of German universities and public interest scientific research institutions. The headquarters is established in Bonn. DFG is an autonomous organization in German scientific community and adopts membership system. The funds are provided by federal government and state governments annually. Article one of DFG regulation is: serve fields of science through funding support for scientific researches. It funds fundamental researches of disciplines like natural science, engineering science, biology, medical science as well as humanistic sociology. Funding projects have more than twenty kinds and funding objects are universities. The total number of funds in 2009 reached 2.2 billion Euros.

The biggest characteristic of evaluation system of scientific research in DFG is the peer review system. It has peer review professional committee, the members of which are nominated more than 200 academic organizations and elected by more than 80,000 German scientists through secret ballot. Scholars who have obtained doctorate for over three years and do researches in universities or academic institutions have the right to elect. The election is held every four years. The professional committee can only be selected successively for once. DFG now has 500 to 600 members of professional committee, representing more than 180 professional disciplines. Nearly 40 professional committees are formed according to classification of disciplines. Experts of humanities and social sciences account for 24.9 percent. The number of foreign evaluation expert increases, accounting for 23.2 percent of the total number of evaluation experts during 2005 and 2007. Experts of humanities and social sciences account for 11 percent of the total number of foreign experts. [7] The most important task of evaluation experts is to evaluate the academic level of projects that submit application and propose appropriate suggestions of financial contribution. Because the evaluation subjects are elected by national academic community, it guarantees the peer review of DFG is scientific, just and authoritative.

\section{The CHE}

CHE is founded in 1994 by German Association of University Presidents and Bertelsmann Foundation, in order to promote and support the reform of German universities. One of the important missions of CHE is to improve the schoolrunning transparency of German universities. CHE selects from disciplines provided by universities and so far has evaluated 41 disciplines. The ranking covers 80 percent of all disciplines of German universities. The first university rankings were publicized in 1998. The evaluation is carried out every three years. 
1) Only evaluate disciplines: CHE adheres to the concept that "there isn't best university but best discipline". A university has preponderant disciplines and weak disciplines. CHE annually establishes one consultative committee for one discipline. Members are representatives of Teachers' Association or Discipline Association and propose suggestions according to index, questionnaire and methods.

2) Multidimensional evaluation: For a certain discipline, the evaluation doesn't base on single index but an index system. The ranking of each discipline includes nine indexes: city, university (scale, foundation time and type), students' characteristics, core issues of courses and teaching, employment and scientific research, teacher and comprehensive evaluation. In scientific research, CHE takes data (financial allocation for scientific research, number of doctor, research reputation and proportion of teachers with doctorate) provided by departments as index, analyzes database (such as science citation index, social sciences citation index, database selected by humanities on domestic publications and database specially provided by Germany for some discipline) through bibliometrics. Because $\mathrm{CHE}$ ranking is multidimensional, they can collect data through various sources and form opinion roundly as well as contrast objective facts with subjective opinions. [8]

3) Announcement of results: CHE ranking results include excellent, medium and poor. CHE has announced ranking results on the Time since 2005. All data and detailed information of universities and specialties are provided on the internet for free. Users have been able to select and determine index weight according to their requirements and preference since 2002 to obtain personalized ranking. The website provides services in English and German languages.

\section{Alexander Von Humboldt Foundation}

Alexander von Humboldt Foundation was founded in Berlin in 1860 in memory of German natural scientist Alexander von Humboldt. It annually provides scholarship for about 600 foreign scientists with doctorate not exceeding 40 years old to serve as visiting scholars in German universities and scientific research institutions.

Central Selection Committee of Alexander von Humboldt Foundation consists of 100 German scientists in various disciplines to select applicants. The selection is presided over by chairman of DFG. The only criterion of selection is academic level instead of nationality, specialty, nation and discipline. Attentions are only paid to academic achievements of applicants. Alexander von Humboldt Foundation only funds individuals instead of projects. Few scholars in humanities and history disciplines succeed in the application. It may be because they are not proficient in German.

According to the number of Alexander von Humboldt Foundation Fellows attracted by every 100 professors, Alexander von Humboldt Foundation determines ranking list of scientific research status and reputation of Germany universities. In August 2014, Alexander von Humboldt Foundation announced scientific research ranking of German universities. The top ten universities are: Free University of Berlin, Humboldt University of Berlin, University of Munich,
University of Bonn, University of Goettingen, Technical University Munich, Heidelberg University, Berlin Institute of Technology, University of Bayreuth, and University of Freiburg.

\section{Self-Evaluation System OF SCIENTIFIC RESEARCH IN UNIVERSITIES (TAKE HUMBOLDT UNIVERSITY OF BERLIN AS AN EXAMPLE)}

Humboldt University of Berlin is the first German university that comprehensively evaluates research and management service, including teaching, research and social service of university. Evaluation objective of scientific research of Humboldt University of Berlin is to provide research activities of university departments, evaluate its quality and judge their academic contributions to universities as decision-making basis of adjusting strategies and allocating resources, in order to supplement and expand research levels.

As pilot project, the research evaluation of Humboldt University of Berlin was launched in winter of 2001. In the trial period of the first year, Humboldt University of Berlin carries out trial evaluation of Department of History, Department of Chemistry and Department of Biology. The research evaluation is presided over by an external committee (represent vice-president of scientific research) every five years. The committee consists of renowned experts who have rich experience in evaluation and peer review in evaluated fields. After each round (every five years) of evaluation is over, department evaluated and vice-president of scientific research in the school formulate an agreement, in which suggestions of evaluation experts on research, promotion of young scholars and policy of equal opportunity for all are recorded and executed. [9]

\section{ANALYSIS ON CHARACTERISTICS OF SCIENTIFIC RESEARCH EVALUATION SYSTEM IN GERMAN UNIVERSITIES}

\section{A. Evaluation of Different Disciplines}

The most important characteristic of scientific research evaluation system of German universities is to evaluate according to different disciplines. The third-party evaluation organizations like WR, DFG and CHE of scientific research in German universities all carry out scientific research evaluation according to disciplines. CHE adheres to the concept that "there isn't best university but best discipline". Wissenschaftsmt divides disciplines into four kinds, namely electronic engineering, chemistry, social studies and British and American studies. DFG divides more than 180 disciplines into 40 professional groups. The evaluation system of scientific research in German universities is carried out for different disciplines.

\section{B. Pay Attention to Peer Review}

The evaluation methods of scientific research in German universities include peer review and using quantitative index. The evaluation of scientific research in Germany focuses on peer review with quantitative index as supplementary mean.

Peer review in Germany attaches importance to quality, ability and character of evaluation experts. The selection of 
experts has strict procedures. It puts a particular emphasis on importance of expert selection and guarantees experts are conflict-free and diversified, international and young, meanwhile their background is diversified. International and young experts in peer review are important to guide the development of scientific research.

\section{Value the Evaluation Quality}

The evaluation system of scientific research in German universities implements the quality guarantee mechanism. First, evaluation method, data source and evaluation results must be open. Second, establish special committee. Experts in the committee reasonably control scientific research evaluation according to different disciplines, evaluation index and questionnaire as well as experience and knowledge of their own. Third, the selection of experts is open worldwide, which guarantees the quality of scientific research evaluation. Fourth, objectives, principles, procedures and specifications of evaluation are clearly defined. Fifth, new evaluation methods must go through trial stage prior to comprehensive evaluation. It guarantees the evaluation system of scientific research in German universities is rigorous and normative with high quality.

\section{Encourage and Train Young Researchers}

To promote the development of young researchers, except for system initiatives (university statutes include training of young researchers) and funding of graduate schools in Excellence Initiative, there are also support and help of researchers. Research departments and career development centers in German universities have provided courses related to soft skills of scientific researches, such as writing, contribution and publication of scientific literature, career development of females in academic sector and the management of third-party funds. In research departments of German universities, professional counselor helps and guides junior researchers to apply projects and funds, in order to encourage and guarantee future development of this discipline.

\section{E. Evaluation Results and Procedures Are Open}

The research results in German universities only have graduation instead of clear ranking. For example, CHE only consists of three grades. The scientific research evaluation of Wissenschaftsmt consists of five grades.

Evaluation method, data source and ranking of scientific research in German universities are open and transparent. CHE specially signs Time to publicize the evaluation results; Wissenschaftsmt publicizes materials related to scientific research evaluation in universities; Alexander von Humboldt Foundation publishes annual report in English and German languages as well as Chinese brochure recently.

\section{F. Pay Attention to Humanities and Social Sciences}

Although humanities and social sciences in Germany enjoy great popularity internationally, under the impact of science and technology, science and technology replaces humanities and social sciences and becomes preponderant discipline in Germany. German government realizes it in scientific research evaluation of Excellence Initiative and has taken some measures. For example, it defines 2007 as the "Year of Humanities and Social Sciences" and pays attention to the balance between the development of science and technology and the development of humanities and social sciences.

\section{ENLIGHTENMENTS OF EVALUATION SYSTEM OF SCIENTIFIC RESEARCH IN GERMAN UNIVERSITIES ON PERFORMANCE EVALUATION OF SCIENTIFIC RESEARCH IN CHINESE UNIVERSITIES}

Essentially, the evaluation system of scientific research in universities conforms to the development pattern of scientific research and the historical tradition of education. University tradition supports the development direction of scientific research evaluation. Germany pays high attention to scientific research and academic freedom of universities and has high academic level. The introduction and analysis on evaluation system of scientific research in German universities indicate the high scientific research level of German universities is positively correlated with its rigorous and diversified evaluation system of scientific research in universities. Experience and enlightenments that our country can absorb are as follows:

\section{A. Establish Multidisciplinary and Multidimensional Evaluation System}

Germany has had multidisciplinary and multidimensional evaluation system of scientific research in universities. Government, third-party organizations and universities as well as university alliance carry out all-round scientific research evaluation of German universities. We should learn from it. Organizations use multidisciplinary evaluation of scientific research in universities. Each discipline has evaluation standards and systems, which are tested prior to popularization.

The government formulates objectives and policies of scientific research evaluation and funds universities, so entrusting third-party organizations to evaluate can make academic freedom and scientific research evaluation of universities develop according to its laws. Besides, third-party evaluation organizations are independent from government and universities and have no interest interrelation with the evaluated, so it effectively avoids correlative profit operators and makes the evaluation fairer. Chinese universities are subordinate to the government and have no independent resources and speaking right. Therefore, third-party evaluation organizations are urgently required to participate in evaluation system of scientific research in universities and establish multidisciplinary and multidimensional evaluation system of scientific research, in order to guarantee the evaluation process and results are objective and fair.

The evaluation purposes of scientific research in German universities are also diversified. Only the evaluation of DFG allocates scientific research funds. The evaluation of evaluation organizations serves as strategic reference for policy advisory and the development of organizations. 
B. Use the Method That Focuses on Peer Review, with Quantitative Evaluation as Supplementary Means

It is generally accepted that the evaluation system of scientific research in German universities combines quantitative evaluation with qualitative evaluation with the latter as the center. [8] The evaluation method of scientific research in Chinese universities still pays attention to quantitative evaluation. The performance evaluation of scientific research depends on quantity of core journals published by teachers, quantity of project host by them, amount of funding and quantity of works. Therefore, university teachers concentrate on writing these and subject application and focus on quantity instead of quality. However, some indexes that cannot be quantified may be more important and can evaluate the scientific research performance of universities, disciplines and professors. The evaluation method of scientific research in Germany that uses peer review with quantitative evaluation as supplementary means should be learnt. Emphasize the quality of scientific research results in promotion and post appointment and give play to the role of incentive mechanism for talents through scientific research evaluation of universities.

\section{Establish and Improve the Quality Guarantee Mechanism of Scientific Research Evaluation}

The evaluation system of scientific research in German universities has rigorous quality guarantee mechanism. Each evaluation organization has strict system to select peer review experts who are international and authoritative; evaluation methods, data source and evaluation results are open; evaluation objectives, procedures and principles are stipulated clearly; test method is applied. The evaluation system of scientific research in Germany attaches importance to analysis and feedback of evaluation results and the training of young scholars. It devotes to the benign development of German universities and education, provides the best opportunity for academic development of young scholars and puts efforts into the future research potential.

\section{Balance between the Development of Science and \\ Technology and the Development of Humanities and Social Sciences}

Universities are the center of scientific and technological innovation and treasury of human civilization and spiritual home of human and concern the system and direction of social development. Universities should create knowledge meanwhile serve the society. Germany separately lists the evaluation system of scientific research in humanities and social sciences and allocates special funds to develop the scientific research of humanities and social sciences. In the improvement of evaluation system of scientific research in the future, our country should separately lists the evaluation system of humanities and social sciences and funds its development, in order to change the situations that universities, scholars of humanities and social sciences in universities are absent from national and social major development projects; universities fail to guide the direction of cultural development. [8]

\section{CONCLUSION}

To sum up, scientific research in Chinese universities plays an increasingly important role in national development, so the establishment and improvement of evaluation system of scientific research are also more and more urgent. Therefore, we can refer to experience of scientific research evaluation in German universities and break the traditional thinking model to establish the evaluation system of scientific research that conforms to China's national condition.

\section{REFERENCES}

[1] CHEPS,Higher Education in Germany, 2007.

[2] Ma Wanhua, Research-oriented Universities in Age of Globalization: Policies and Practice in America, Britain, Japan and Germany [M], Education Science Press, May 2013, P221

[3] https://www.wissenschaftsrat.de/download/archiv/pilot_866508_Sociology.pdf

[4] Li Xiaoxuan. Evaluation Practice of German Scientific Research Institutions and Enlightenment [J], Bulletin of Chinese Academy of Sciences, 2004, 19(4): 274-277

[5] Research Group for Analysis Report on German Scientific and Technological Innovation, Analysis Report on German Scientific and Technological Innovation [M], Beijing: Science Press, 2014(21): 57-58, 258-262

[6] Zhang Zhe. Evaluation System Should Reflect Quality of Academic Institutions: Interview Verna Lange, Director of German Scientific Committee Research Department [N], Chinese Social Sciences Today, Feb.25, 2013 (419)

[7] Han Zhiyong, Zhao Shikui. Systematic Analysis of Evaluation Experts of DFG and References [J], Science and Technology Progress and Policy, April 2012

[8] Liu Niancai, John Sadlak, World-class Universities: Characteristics, Ranking, Construction $[\mathrm{M}]$, Shanghai Jiaotong University Press, April 2007, P216, P216, P242.

[9] Liao Yi. Evaluation on University Discipline and Specialty [D], Xiamen: $\mathrm{PhD}$ thesis of Xiamen University, 2007: P94. 